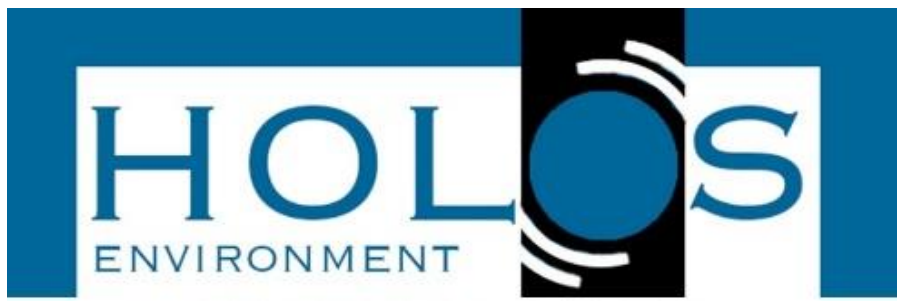

\title{
CONCEITO DE PRECIPITAÇÃO PROVÁVEL APLICADO AO DIMENSIONAMENTO DE RESERVATÓRIOS PARA APROVEITAMENTO DE ÁGUAS PLUVIAIS
}

\section{CONCEPT OF PROBABLE RAINFALL APPLIED TO THE DESIGN OF RAINWATER RESERVOIRS}

\author{
Kelly Milene Rodrigues Silva ${ }^{1}$; André Vinícius Rodrigues Silva ${ }^{1}$; \\ Michael Silveira Thebaldi ${ }^{1}$; Letícia Cintra Gonzaga Iwata ${ }^{1}$; Lidiane Machado Silva ${ }^{1}$
}

Artigo recebido em: 23/04/2018 e aceito para publicação em: 06/09/2018.

DOI: http://dx.doi.org/10.14295/holos.v18i2.12289

Resumo: Cada vez mais é evidente os problemas relacionados a crise hídrica, portanto há a necessidade de encontrar soluções para uso de água com menor qualidade para fins não potáveis, sendo o aproveitamento de águas pluviais relevante. Diante disso, o presente trabalho foi desenvolvido com o intuito de analisar de maneira técnica a aplicação da Precipitação Provável na obtenção do volume de reservatórios para armazenamento de águas pluviais em residências do município de Formiga - MG. Para tal, as precipitações prováveis mensais e anual, foram ajustadas seguindo a distribuição Gama, sendo então simulado o volume de reservatórios para armazenamento de águas pluviais, a partir de diferentes precipitações prováveis mensais e anuais e métodos de cálculo, apresentados pela NBR 15527, além da consideração de demandas por recurso hídrico não potável. Observou-se que o mês de julho é o que apresenta menor precipitação no município, não importando a probabilidade considerada para essa, enquanto que as maiores precipitações prováveis são obtidas em dezembro e janeiro. Em escala anual, a maior precipitação provável é de 1564,54 $\mathrm{mm}$ enquanto a menor, $935,19 \mathrm{~mm}$. Segundo os resultados obtidos, a aplicação do conceito de precipitações prováveis é mais efetiva ao se usar os métodos de Rippl e Prático Australiano, por estes apresentarem maiores diferenças absolutas entre volumes de reservatório obtidos a partir das diferentes precipitações. Todavia os dois possuem comportamentos antagônicos quanto à consideração de maiores ou menores lâminas precipitadas.

Palavras-chave: Desenvolvimento sustentável. Hidrologia estatística. Hidrologia urbana. Gerenciamento de recursos hídricos. Instalações hidráulicas.

\begin{abstract}
Problems related to the water crisis are increasingly evident, so there is a need to find solutions for the use of lower quality water for non-potable purposes, being the use of rainwater interesting. Therefore, the present paper was developed with the purpose to analyze the application of Probable Rainfall concept to obtain the volume of reservoirs for rainwater storage in residences of the municipality of Formiga, MG, Brazil, in a technical way. For such, the monthly and annual probable rainfall were adjusted following the Gamma distribution, being the volume of rainwater reservoirs simulated, based on different monthly and annual probable rainfall and calculation methods presented by ABNT 15527, in addition to considering non-potable water demands. It was observed that the month of July shows the lowest precipitation in the municipality,
\end{abstract}

\footnotetext{
1 Universidade Federal de Lavras (UFLA), Lavras, MG. E-mails: (kellymilene2010@hotmail.com, andrerodriguesvs@gmail.com, michael.thebaldi@deg.ufla.br, milyiwata@hotmail.com, lidianesilvamachado@hotmail.com)
} 
regardless of the probability considered for this, while the highest probable precipitations are obtained in December and January. On an annual scale, the highest probable precipitation is $1564.54 \mathrm{~mm}$ while the lowest, $935.19 \mathrm{~mm}$. According to the results, the application of the concept of probable rainfall is more effective when using the Rippl and Australian Practical Methods, as they present greater absolute differences between reservoirs volumes obtained from the different precipitations. However, the two have antagonistic behaviors regarding the consideration of larger or smaller precipitated water depths.

Palavras-chave: Sustainable development. Statistical hydrology. Urban hydrology. Water resources management. Water supply facilities.

\section{INTRODUÇÃO}

É notável a insuficiência e a degradação da água doce no planeta, do ponto de vista ambiental (BERTOLO, 2006). Além disso, de acordo com Tomaz (2003), cerca de 97,5\% da água no planeta é salina, e os outros $2,5 \%$ correspondem a água doce, além de que, $68,9 \%$ da água doce existente estão congeladas. A água armazenada em lençóis subterrâneos corresponde a $29,9 \%$ da água doce. As águas encontradas em riachos, lagoas e reservatórios correspondem à $0,266 \%$, o que significa $0,007 \%$ da água absoluta do mundo. Por isso, segundo Oliveira (2008), o aproveitamento de águas pluviais se faz uma prática comum, em quase todo o planeta, sobretudo em regiões de clima árido e semiárido.

Em municípios maiores com população concentrada e grandes áreas impermeabilizadas, uma chuva intensa de cerca de $40 \mathrm{~mm} / \mathrm{h}$ pode acarretar inundações inesperadas. Uma precipitação assim não é difícil de ocorrer e, nem traz graves consequências em áreas puramente vegetadas (SOUZA, 2011). Segundo o mesmo autor, impactos negativos associados à precipitação não podem ser associados à chuva, mas sim, à falta de alocamento correto de recursos e infraestrutura, principalmente.

Segundo Tucci (2015), um dos fatores que tem produzido grande aumento na frequência das inundações está associado a problemas inerentes ao desenvolvimento urbano. No Brasil, as enchentes são geradas principalmente pela falta de disciplinamento da ocupação urbana e de infraestrutura para a correta drenagem urbana. Devido à impermeabilização do solo e à construção da rede de condutos pluviais, as enchentes aumentam a sua frequência e magnitude. $O$ desenvolvimento urbano também pode provocar obstruções ao escoamento, como aterros, pontes, drenagens inadequadas e assoreamento (TUCCI, 2005). 
Uma maneira de reduzir o impacto ambiental das águas pluviais é a reserva dessa água para posterior utilização para fins não-potáveis. O sistema para aproveitamento da água pluvial consiste em instalações hidráulicas e reservação independentes dos demais sistemas prediais. Em residências unifamiliares, a implantação desse tipo de sistema depende do custo do investimento, sobretudo em famílias de renda baixa (MORUZZI et al., 2008).

Para o correto dimensionamento dos reservatórios para captação e uso de águas pluviais, além do conhecimento da demanda por recurso hídrico não potável, deve-se possuir dados acerca do comportamento histórico da chuva na região em estudo. Nos métodos propostos para determinação do volume de reservatórios propostos pela NBR 1527/2007 (ABNT, 2007), são utilizados dados médios de precipitações mensais e anual.

Neste sentido, autores como Oliveira e Carvalho (2003), Sampaio et al. (2006) e Soccol et al. (2010), orientam a realização de dimensionamentos de projetos hidráulicos tomando como referência a precipitação provável, pois o uso de valores médios, pode resultar em superdimensionamentos, já que estes podem apresentar baixas probabilidades de ocorrência.

De acordo com Mantovani et al. (2009), entende-se como sendo a precipitação provável a precipitação almejada de acordo com a perspectiva e com certa expectativa do acontecimento, ou seja, é a menor chuva aguardada em um determinado período do ano a um dado nível de probabilidade.

Existem diversas metodologias para ser obtida a precipitação provável de uma determinada região. Essa avaliação de precipitação, por meio de probabilidade, é de fundamental importância para planejamentos para um dimensionamento seguro de obras, na construção civil e na engenharia de águas e solos (FRIZZONE et al., 2005), possibilitando antevisões e melhores aplicações de técnicas.

É preciso coletar os dados necessários e, em seguida ajustá-los a algumas distribuições estatísticas, a fim de se determinar em qual destas o item em estudo mais se adequa, para que haja o mínimo de falha na estimativa (FONSECA, 2012). Algumas destas distribuições são: distribuições de probabilidade Gumbel para Máximos, Fréchet, Gama 2 parâmetros, Log-Normal 2 parâmetros e Log-Normal 3 parâmetros.

Diante do exposto, o objetivo deste trabalho foi analisar tecnicamente o emprego do conceito de Precipitação Provável na obtenção do volume de reservatórios para 
armazenamento de águas pluviais em Formiga - MG, a partir de chuvas com diferentes frequências de excedência nas escalas de tempo mensal e anual.

\section{MATERIAL E MÉTODOS}

Para a determinação do volume dos reservatórios de águas pluviais, foram definidos cenários em que foram fixados os seguintes parâmetros: demanda diária de água potável 90, 150, 270 e 450 litros per capita em residências ocupadas por três moradores, e, porcentagem de substituição de água potável por pluvial de 30\% para uma área de captação de $100 \mathrm{~m}^{2}$. A partir disso, foram obtidas as demandas por água pluvial mensais e anual.

O município de Formiga possui área de 1502 km², localiza-se no Oeste de Minas Gerais e é constituído pelos biomas Cerrado e Mata Atlântica. De acordo com a Classificação Climática de Köppen se enquadra no clima Cwb, ou seja, clima temperado úmido com inverno seco e verão temperado (Alvares et al., 2013). A série histórica de precipitação do município de Formiga - MG, foi obtida da aplicação web Hidroweb, gerenciado pela Agência Nacional das Águas (ANA). Os dados de precipitação pluviométrica foram organizados com objetivo de obter as precipitações prováveis mensais, a partir da totalização das precipitações diárias a cada mês e anuais, procedendo-se a totalização das precipitações mensais de cada ano. Foram utilizadas informações dos períodos entre 1925 a 1937, 1976 a 2005 e 2007 a 2014, sendo que os anos de 1924, 1938 a 1975 a 2006 não foram utilizados por não se tratarem de séries completas. As frequências observadas das precipitações foram calculadas pela fórmula de Weibull (Equação 1).

$$
\mathrm{f}_{\mathrm{obs}}=\frac{\mathrm{i}}{\mathrm{N}+1}
$$

em que:

i = Posição que o dado ocupa dentro da série histórica; e

$\mathrm{N}=$ Tamanho da série histórica.

Os dados de precipitação mensal e anual foram alocados de forma decrescente, com o objetivo de adquirir a frequência de excedência. Para a determinação das precipitações prováveis mensais e anuais, foram ajustadas de acordo com a Função de Cumulativa de 
Probabilidade Gama a 2 parâmetros (Equação 2). Os parâmetros da distribuição Gama ( $\beta$ e u) são dados pelas Equações 3 e 4 .

$$
\begin{gathered}
\mathrm{FCP}=\frac{1}{\beta^{v} \cdot \Gamma(v)} \int_{0}^{\mathrm{x}} \mathrm{u}^{(v-1)} \mathrm{e}^{\frac{-\mathrm{u}}{\beta}} \mathrm{du} \\
\beta=\frac{S^{2}}{\overline{\mathrm{X}}} \\
v=\frac{(\overline{\mathrm{X}})^{2}}{S^{2}}
\end{gathered}
$$

em que:

$\mathrm{S}^{2}=$ desvio padrão amostral da série histórica;

$\overline{\mathrm{X}}=$ média amostral da série histórica.

Os dimensionamentos dos reservatórios foram obtidos por meio dos métodos de Rippl, da Simulação, Azevedo Neto, Prático Alemão, Prático Inglês e Prático Australiano adaptados a partir de sua apresentação na NBR 15527 (ABNT, 2007) seguindo os cenários estabelecidos e substituindo-se a utilização das precipitações médias mensais e anual pelas precipitações prováveis mensais e anuais com diferentes probabilidades de ocorrência $(95,85,75,50$ e $25 \%)$.

\section{RESULTADOS E DISCUSSÃO}

Os parâmetros de ajuste da distribuição de probabilidade Gama para as precipitações mensais totais e anual de Formiga - MG são mostrados na Tabela 1. 
Tabela 1 - Parâmetros de ajuste da distribuição Gama para séries de precipitação mensal e anual do município de Formiga - MG

\begin{tabular}{ccc}
\hline Mês & \multicolumn{3}{c}{ Parâmetros } \\
& 59,9932 & $u$ \\
\hline Janeiro & 52,9357 & 4,48904 \\
Fevereiro & 39,6258 & 3,46262 \\
Março & 32,7794 & 3,98473 \\
Abril & 31,7398 & 2,15427 \\
Maio & 30,3974 & 1,29336 \\
Junho & 27,129 & 0,54597 \\
Julho & 29,197 & 0,53651 \\
Agosto & 35,5278 & 0,63195 \\
Setembro & 35,3963 & 1,6126 \\
Outubro & 28,0976 & 3,25042 \\
Novembro & 32,83256 & 8,05857 \\
Dezembro & 62,34354 & 8,457889 \\
Anual & & 22,12969
\end{tabular}

A partir destes foram determinadas precipitações prováveis, destas séries históricas, com níveis de probabilidade de ocorrência de 95, 85, 75, 50 e 25\%. A precipitação provável mensal estimada pode então, ser visualizada na Figura 1.

Figura 1 - Precipitação provável mensal com excedência de 95\%, 85\%, 75\%, 50\% e $25 \%$ para o município de Formiga - MG

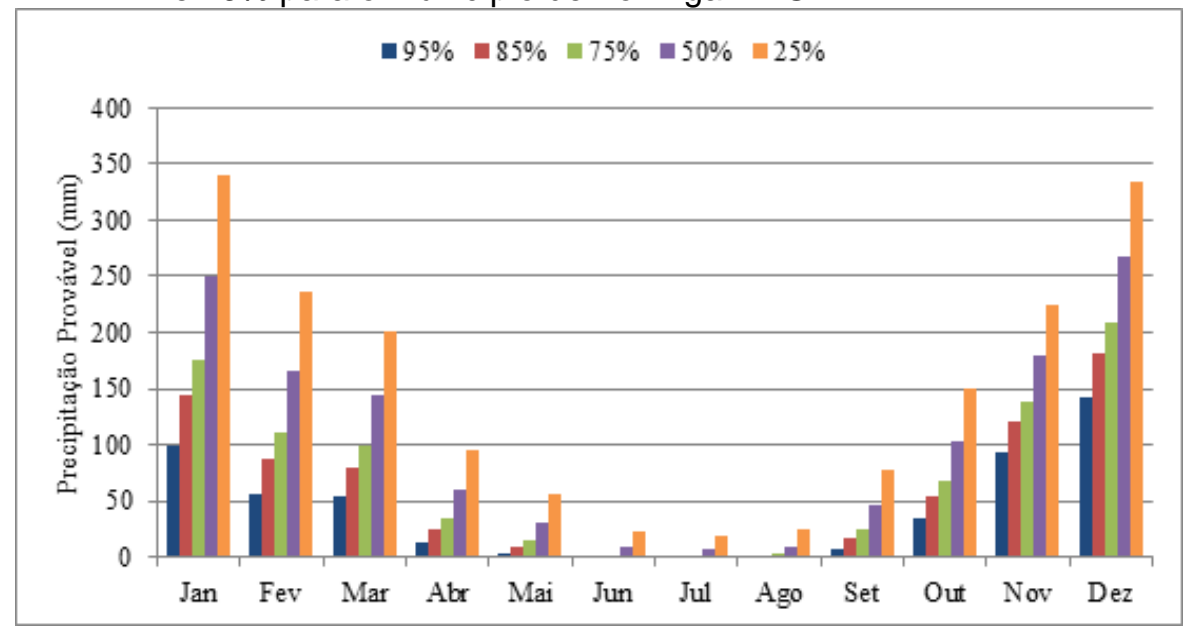


Para uma frequência de excedência de $95 \%$, a maior precipitação provável encontrada foi de $141,37 \mathrm{~mm}$, no mês de dezembro. Já a menor foi de $0,08 \mathrm{~mm}$ no mês de julho. Analisando a probabilidade de excedência de $90 \%$, a maior precipitação foi 164,48 $\mathrm{mm}$ em dezembro, e a menor $0,29 \mathrm{~mm}$, em julho. Considerando uma frequência de excedência $75 \%$ encontramos a máxima de 208,77 mm em dezembro e a mínima de 1,70 $\mathrm{mm}$ em julho. Para a probabilidade de $50 \%$, foi encontrada a máxima precipitação provável de 266,82 mm em dezembro e a mínima de 7,03 em julho. Por fim, para a frequência de $25 \%$ a maior precipitação foi $340,85 \mathrm{~mm}$, em janeiro, e a menor $19,46 \mathrm{~mm}$, em julho.

Pode-se inferir, que no município de Formiga - MG, as maiores lâminas de precipitação ocorrem em dezembro e janeiro, já a menor quantidade de precipitação pôde ser observada no mês de julho. Já as precipitações prováveis anuais para o município estudado, podem ser vistas na Figura 2.

Figura 2 - Precipitação provável anual com excedência de 95\%, 85\%, 75\%, $50 \%$ e $25 \%$ para o município de Formiga - MG

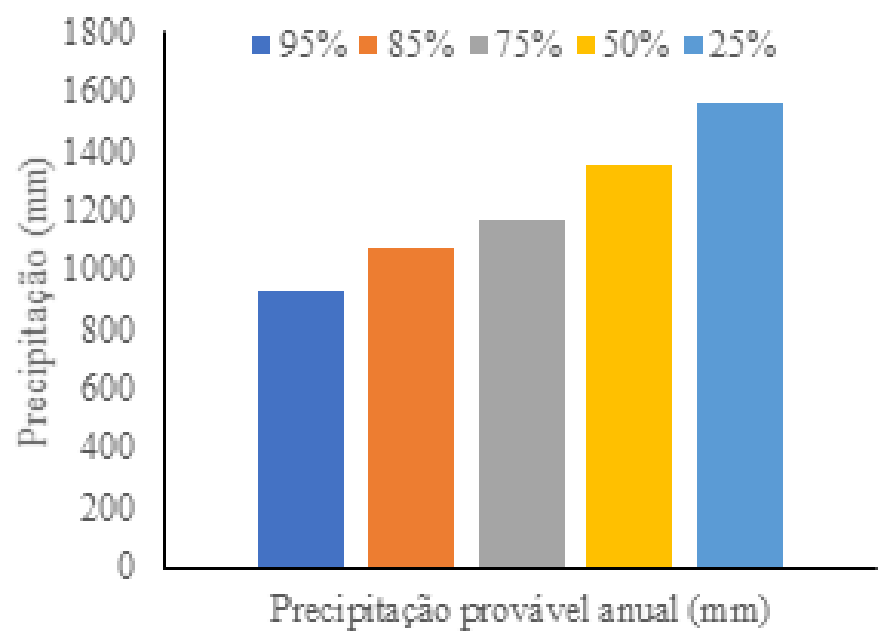

Em se tratando de precipitação provável anual, ao se analisar a frequência de excedência de $95 \%$, foi determinada uma precipitação de 935,19 mm. Analisando a probabilidade de excedência de $85 \%$ tem-se $1079,5 \mathrm{~mm}$. Para excedência de $75 \%$ foi calculada uma lâmina precipitada de 1172,17 mm. Já ao se considerar uma probabilidade de ocorrência da precipitação de 50\%, foi encontrada uma precipitação provável anual de $1.358,91 \mathrm{~mm}$, e, por fim, para a excedência de $25 \%$ foi determinada uma precipitação provável anual de 1564,54 mm. 
A partir das precipitações prováveis calculadas, os volumes do reservatório de água pluvial, para uma demanda de $90 \mathrm{l} / \mathrm{dia}$, em função dos diferentes métodos de dimensionamento e probabilidades de ocorrência de precipitação são mostrados na Tabela 2.

Tabela 2 - Volumes do reservatório de água pluvial, em $\mathrm{m}^{3}$, para uma demanda de $90 \mathrm{l} / \mathrm{dia}$, em função aos diferentes métodos de dimensionamento e probabilidades de ocorrência de precipitação

Método de dimensionamento do reservatório

Probabilidade de ocorrência da precipitação (\%)

\begin{tabular}{cccccc}
\cline { 2 - 6 } & 95 & 85 & 75 & 50 & 25 \\
\hline Rippl & 13,93 & 11,09 & 9,19 & 5,76 & 1,59 \\
Azevedo Neto & 23,57 & 27,20 & 29,54 & 34,24 & 39,43 \\
Prático Alemão & 1,970 & 1,970 & 1,970 & 1,970 & 1,970 \\
Prático Inglês & 4,68 & 5,40 & 5,86 & 6,79 & 7,82 \\
Prático Australiano & 13,25 & 24,77 & 37,86 & 68,86 & 109,93 \\
\hline
\end{tabular}

Nota-se, pela análise da Tabela 2 que, para o Método de Rippl, os volumes calculados dos reservatórios diminuem com a consideração de precipitações com probabilidades de ocorrência menores, variando de 13,93, para $95 \%$ de probabilidade de ocorrência, a $1,59 \mathrm{~m}^{3}$, para nível de $25 \%$. Isso se deve pelo fato da precipitação com probabilidade de $25 \%$ possui lâmina maior, fazendo então que a produção de água pluvial tenha maior magnitude sobre a demanda, fixada em 90 litros por dia.

Para um ano seco, portanto, ter-se-ia a necessidade de um reservatório de maior volume, de forma a atender as demandas por água não potável: o volume de reserva previsto ao se considerar uma chuva com probabilidade de ocorrência de $95 \%$ para este método, é, aproximadamente 8,76 vezes maior que para probabilidade de $25 \%$. Tecnicamente, ao considerar as chuvas com probabilidade de ocorrência de 95 e $85 \%$, se usaria o mesmo reservatório, 15000 litros. Para as demais probabilidades, 10000, 7500 e 2000 litros, com 75, 50 e $25 \%$, respectivamente.

Já para o método de Azevedo Neto, há comportamento inverso do obtido para o Método de Rippl: quanto menor a lâmina de chuva considerada, ou seja, a produção de água pluvial, menor o volume, obtendo-se então, menor volume de reservatório para probabilidade de ocorrência de precipitação de $95 \%$. Porém, como pode ser visto na tabela 
2, o menor volume previsto pelo método de Azevedo Netto supera o maior previsto no Método de Rippl. Os valores obtidos pelo Método de Azevedo Netto foram mais homogêneos, tendo diferença de apenas aproximadamente 1,67 vezes entre o menor $\left(23,57 \mathrm{~m}^{3}-25 \%\right)$ e o maior $\left(39,43 \mathrm{~m}^{3}-95 \%\right)$.

O cálculo do volume de reservatório para aproveitamento de águas pluviais pelo Método Prático Alemão é realizado considerando o que for menor entre o volume precipitado aproveitável e o volume anual de consumo. Para a demanda diária de $90 \mathrm{l} / \mathrm{dia}$, o menor volume obtido foi o aproveitado do precipitado para todas as precipitações prováveis anuais. Assim, não houve aplicabilidade em se determinar as precipitações prováveis nesta situação. O volume obtido de reservatório de águas pluviais neste método, como visto na Tabela 2, é um pouco superior ao obtido para método de Rippl ao considerar precipitação com probabilidade de $25 \%$ de ocorrência, ou seja, uma lâmina total anual maior que as demais avaliadas.

Assim como ocorrido para o Método de Azevedo Netto, para o Método Prático Inglês os volumes de reservatório de águas pluviais crescem com a consideração de uma lâmina precipitada maior. Estes métodos consideram que quanto mais água produzida, mais esta deverá e poderá ser reservada. Dessa forma, se for utilizada precipitação com altas probabilidades de ocorrência no dimensionamento do reservatório de águas pluviais por este método, em anos com maiores precipitações, o recurso hídrico não poderá ser reservado a contento, o que seria caracterizado como desperdício. Assim como ocorrido para o Método de Azevedo Netto, o maior reservatório calculado pelo Método Prático Inglês foi 1,67 vezes maior que o menor reservatório. Uma particularidade destes dois métodos é que estes não consideram os volumes demandados.

Analisando-se a metodologia proposta para estes dois últimos, os métodos Azevedo Neto e Prático Inglês apresentam resultados proporcionais aos dados pluviométricos e áreas de captação de água pluvial (AMORIM; PEREIRA, 2008), assim, quanto menor a probabilidade de ocorrência da precipitação adotada para o dimensionamento, maior o volume do reservatório.

O dimensionamento dos reservatórios de água pluvial pelo Método Prático Australiano foi o que apresentou maior discrepância entre volumes em função da consideração de diferentes probabilidades de ocorrência da precipitação (Tabela 2). Ao se prever ano com muita precipitação para dimensionamento (chuva com probabilidade de 
ocorrência de 25\%), o reservatório calculado teria volume de 109,93 $\mathrm{m}^{3}$, muito superior a qualquer outro obtido, o que traria impacto no investimento de capital financeiro para sua aquisição. O menor volume obtido para este método é similar ao maior obtido para o Método de Rippl - 13,25 e 13,93 $\mathrm{m}^{3}$, respectivamente. A comparação entre o menor e maior volume de reservatório obtidos para este método indica que aquele é 8,30 vezes menor, aproximadamente.

Para este último método, em alguns casos, é preciso um superdimensionamento do volume para atender a confiança necessária, assim como obtido no trabalho desenvolvido por Minikowski e Maia (2009), que citam que, na aplicação do Método Prático Australiano, pode-se obter reservatórios de maior porte; que, apesar de proporcionarem maior atendimento das demandas, podem inviabilizar a sua implantação do ponto de vista econômico.

Os volumes do reservatório de água pluvial, para uma demanda de 150 l/dia, em função dos diferentes métodos de dimensionamento e probabilidades de ocorrência de precipitação são mostrados na Tabela 3.

Tabela 3 - Volumes do reservatório de água pluvial, em $\mathrm{m}^{3}$, para uma demanda de $150 \mathrm{l} / \mathrm{dia}$, em função dos diferentes métodos de dimensionamento e probabilidades de ocorrência de precipitação

\begin{tabular}{cccccc}
\hline \multirow{2}{*}{ Método de dimensionamento do reservatório } & \multicolumn{5}{c}{ Probabilidade de ocorrência da precipitação (\%) } \\
\cline { 2 - 6 } & 95 & 85 & 75 & 50 & 25 \\
\hline Rippl & 26,21 & 22,07 & 19,34 & 12,82 & 7,11 \\
Azevedo Neto & 23,57 & 27,20 & 29,54 & 34,24 & 39,43 \\
Prático Alemão & 3,29 & 3,29 & 3,29 & 3,29 & 3,29 \\
Prático Inglês & 4,68 & 5,40 & 5,86 & 6,79 & 7,82 \\
Prático Australiano & 9,59 & 14,98 & 19,46 & 46,96 & 88,03 \\
\hline
\end{tabular}

Pode-se observar na Tabela 3 que, pelo método de Rippl o volume do reservatório diminui quando a probabilidade de ocorrência da precipitação também diminui, variando de 26,21 $\mathrm{m}^{3}$, para 95\% de probabilidade de ocorrência a 7,11 $\mathrm{m}^{3}$, para um nível de probabilidade de $25 \%$. O volume de água a ser reservada para a precipitação considerada 95\% é aproximadamente 3,67 vezes maior do que para a probabilidade de $25 \%$.

Já para o cálculo dos volumes de reservatório pelo método Prático Alemão com uma demanda de 150 l/dia, o menor volume obtido entre a demanda e o volume de precipitação que pode ser aproveitado, foi o de precipitação não importando a precipitação provável 
adotada. Desta maneira, não importando a lâmina provável adotada para o dimensionamento, o volume do reservatório foi o mesmo.

No método Prático Australiano o dimensionamento dos reservatórios para aproveitamento de água pluvial foi o que mostrou ser o mais inviável, devido aos grandes volumes de reservatório, porém, o mais influenciável pelas considerações de precipitações com diferentes probabilidades de ocorrência (Tabela 3). Considerando um ano com muita precipitação (25\% de probabilidade de ocorrência), o reservatório calculado apresenta $88,03 \mathrm{~m}^{3}$, um volume aproximadamente 9,18 vezes maior, que uma probabilidade menor $9,59 \mathrm{~m}^{3}$.

Os volumes do reservatório de água pluvial, para uma demanda de 270 l/dia, em função dos diferentes métodos de dimensionamento e probabilidades de ocorrência de precipitação são mostrados na Tabela 4.

Tabela 4 - Volumes do reservatório de água pluvial, em $\mathrm{m}^{3}$, para uma demanda de $270 \mathrm{l} / \mathrm{dia}$, em função dos diferentes métodos de dimensionamento e probabilidades de ocorrência de precipitação

\begin{tabular}{cccccc}
\hline \multirow{2}{*}{ Método de dimensionamento do reservatório } & \multicolumn{5}{c}{ Probabilidade de ocorrência da precipitação (\%) } \\
\cline { 2 - 6 } & 95 & 85 & 75 & 50 & 25 \\
\hline Rippl & 56,81 & 47,41 & 42,85 & 33,18 & 21,15 \\
Azevedo Neto & 23,57 & 27,20 & 29,54 & 34,24 & 39,43 \\
Prático Alemão & 5,61 & 5,91 & 5,91 & 5,91 & 5,91 \\
Prático Inglês & 4,68 & 5,40 & 5,86 & 6,79 & 7,82 \\
Prático Australiano & 2,94 & 7,66 & 11,33 & 19,15 & 44,23 \\
\hline
\end{tabular}

Assim como ocorrido para as outras demandas, no método de dimensionamento Rippl, nota-se que volume do reservatório diminui quando a probabilidade de ocorrência também diminui, variando de 56,81 $\mathrm{m}^{3}$ para uma precipitação provável de $95 \%$ a $21,15 \mathrm{~m}^{3}$ para um nível de $25 \%$.

Para a demanda de $270 \mathrm{l} / \mathrm{dia}$, considerando os volumes de reservatório de águas pluviais calculados para o método de Rippl e as precipitações prováveis mensais avaliadas, se obtiveram-se resultados mais homogêneos (diferença de aproximadamente 2,69 vezes entre o menor e o maior reservatório obtido) quando comparados aos mostrados nas Tabelas 2 e 3. 
Novamente, para o método Prático Alemão, não foram obtidas diferenciações entre volumes de reservatórios para a demanda por água não potável de 270 1/dia (Tabela 4), sendo obtido o volume constante de 5,91 m² não importando a precipitação provável.

Pelo método Prático Australiano, a um nível de probabilidade de ocorrência de $25 \%$ da precipitação, obteve-se um volume de $44,23 \mathrm{~m}^{3}$, aproximadamente 15,05 vezes maior do que para a precipitação com probabilidade de ocorrência de $95 \%$.

Os volumes do reservatório de água pluvial, para uma demanda de $450 \mathrm{l} / \mathrm{dia}$, em função dos diferentes métodos de dimensionamento e probabilidades de ocorrência de precipitação são mostrados na Tabela 5.

Tabela 5 - Volumes do reservatório de água pluvial, em $\mathrm{m}^{3}$, para uma demanda de $450 \mathrm{l} / \mathrm{dia}$, em função dos diferentes métodos de dimensionamento e probabilidades de ocorrência de precipitação

\begin{tabular}{cccccc}
\hline \multirow{5}{*}{ diferentes métodos de dimensionamento e probabilidades de ocorrência de precipitação } \\
\hline \multirow{2}{*}{ Método de dimensionamento do reservatório } & \multicolumn{4}{c}{ Probabilidade de ocorrência da precipitação (\%) } \\
\cline { 2 - 6 } & 95 & 85 & 75 & 50 & 25 \\
\hline Rippl & 114,17 & 96,85 & 86,83 & 69,72 & 52,73 \\
Azevedo Neto & 23,57 & 27,20 & 29,54 & 34,24 & 39,43 \\
Prático Alemão & 5,61 & 6,48 & 7,03 & 8,15 & 9,39 \\
Prático Inglês & 4,68 & 5,40 & 5,86 & 6,79 & 7,82 \\
Prático Australiano & 0,00 & 0,57 & 2,75 & 8,17 & 17,35 \\
\hline
\end{tabular}

Como se pode verificar na Tabela 5, o método Rippl se comporta da mesma maneira aplicado a diferentes demandas, ou seja, o volume do reservatório diminuiu quando a probabilidade de ocorrência da precipitação também diminui, variando de 114,17 $\mathrm{m}^{3}$ para uma probabilidade de $95 \%$, para $52,73 \mathrm{~m}^{3}$, para um nível de probabilidade de $25 \%$. Isso se deve ao fato de probabilidade de precipitação de $25 \%$ gerar uma lâmina de água maior, fazendo com que a produção de água seja maior para a demanda de $450 \mathrm{l} / \mathrm{dia}$. Com a análise dos resultados obtidos para o método de Rippl considerando todas as demandas estudadas e precipitações prováveis, tem-se que quanto maior a demanda considerada, menor a diferença entre volumes obtidos considerando lâminas diferentes de precipitação, e maiores os volumes absolutos de reservatórios.

De acordo com Cohim et al. (2008), a diferença que se encontra entre os resultados obtidos na utilização do Método de Rippl se dá devido à quantidade de chuva e a forma como as precipitações se distribuem ao longo do ano, neste estudo, em função das diferentes probabilidades de ocorrência. 
Sperancetta et al. (2004) explicam a simplicidade deste método como um balanço das entradas e saídas de água, em um reservatório hipotético, que deve suprir a demanda em períodos de carência de chuvas. Isso se confirma na análise dos resultados obtidos para os volumes de reservatório calculados para as maiores probabilidades de ocorrência de precipitação, que geram menores lâminas precipitadas, justamente para suprir as demandas em períodos em que não há chuva suficiente.

Desta forma, a aplicação do conceito de precipitação provável para este método se mostra menos relevante se as demandas forem maiores. Para pequenas demandas, ao se considerar chuvas com maiores probabilidades de ocorrência, os reservatórios serão maiores, podendo ser armazenados maiores volumes de água não potável, atendendo também, a períodos de maior precipitação.

Diferentemente do obtido anteriormente, houve variação dos volumes de reservatório pelo obtido pelo método Prático Alemão ao se ter a demanda de $450 \mathrm{l} / \mathrm{dia}$, que é alta. Desta forma, o volume anual precipitado aproveitável foi menor que o anual de consumo, nos casos de precipitações prováveis com nível de ocorrência de 95\%, 85\%, 75\% e 50\%. Assim, a adoção, no dimensionamento do reservatório de aproveitamento de águas pluviais para fins não potáveis, de diferentes probabilidades de ocorrência da chuva só tem aplicabilidade para altas demandas, quando se optar pelo uso do Método Prático Alemão.

Segundo Fontanela (2010), o Método Prático Alemão, se assemelha, em partes, ao Método Prático Inglês, diferindo dele ao comparar o volume de chuva aproveitável com a demanda anual. Desta maneira, em alguns casos da aplicação do Método Prático Alemão, foi considerada apenas a demanda por recurso hídrico não potável, não levando em consideração a precipitação provável aproveitável.

O método Prático Australiano não se mostrou adequado para essa demanda quando consideradas épocas em que se teria pouca chuva no dimensionamento. Por exemplo, quando se utilizou precipitação com $95 \%$ de ocorrência, ou seja, baixa, este método não previu volume de reservatório, já que as demandas superam, de maneira relevante, a produção de recurso hídrico não potável (Tabela 5).

No geral, com o uso do Método Prático Australiano, se forem consideradas precipitações prováveis de baixa frequência de ocorrência, volumes exagerados de reservatório são obtidos, sendo ainda maiores quanto menor a demanda. Isso pode inviabilizar a aquisição ou construção destes devido ao investimento financeiro. 
Sem esta análise financeira, se o usuário desejar grandes volumes de reservatório de forma a aproveitar todo o potencial de produção de água pluvial, a precipitação provável de $25 \%$ deve ser considerada, ou seja, devem-se esperar precipitações acima da média.

\section{CONCLUSÕES}

Pela análise dos resultados obtidos, é correto afirmar que com o uso dos parâmetros de ajuste da distribuição Gama para séries de precipitação mensal e anual do município de Formiga - MG, foi possível determinar as precipitações mensais e anuais com probabilidades de ocorrência de $95 \%, 85 \%, 75 \%, 50 \%$ e $25 \%$. Com isso, foi notório que o mês de julho é o mais seco do município, à medida que a maior precipitação provável foi no mês de janeiro, com probabilidade de ocorrência de $25 \%$. No embasamento geral do ano, a maior precipitação provável é de $1564,54 \mathrm{~mm}$, enquanto que a menor é cerca de $935,19 \mathrm{~mm}$.

Os métodos de dimensionamento de reservatórios de água não potável apresentaram diferentes comportamentos quando receberam, em seu cálculo, as precipitações prováveis determinadas. De início, para o Método de Rippl, as precipitações menos prováveis exigem reservatórios de volumes menores, em vista que, para Azevedo Neto, os métodos Prático Inglês e o Australiano, demandam volumes maiores, já que têm como objetivo captar o máximo de água. Porém, se comparados esses dois últimos métodos, o Prático Australiano apresentou valores exorbitantes de reservatórios para certas precipitações prováveis.

O método menos influenciado pelas diferentes precipitações, foi o Método Prático Alemão, enquanto que o Método Prático Inglês não é influenciado pelas diferentes demandas de água pluvial.

Portanto, o emprego do conceito de precipitações prováveis é mais eficaz ao se utilizar os métodos de Rippl e o Prático Australiano, pois esses apresentam maiores diferenças absolutas entre os volumes de reservatórios, com base em diferentes precipitações. Ainda que os dois possuem concepções e comportamentos contraditórios em relação ao nível de lâminas precipitadas. 


\section{REFERÊNCIAS}

ALVARES, C. A.; STAPE, J. L.; SENTELHAS, P. C.; GONÇALVES, J. L. M.; SPAROVEK, G. Köppen's climate classification map for Brazil. Meteorologische Zeitschrift, v. 22, n. 6, p. 711-728, 2013.

ASSOCIAÇÃO BRASILEIRA DE NORMAS TÉCNICAS (ABNT). NBR 15527 - Água de chuva: aproveitamento de coberturas em áreas urbanas para fins não potáveis: requisitos. Rio de Janeiro, 2007.

BERTOLO, E. J. P. Aproveitamento da água da chuva em edificações. 2006. 204 f. Dissertação (Mestrado em Engenharia do Ambiente) - Faculdade de Engenharia da Universidade do Porto, Porto, 2006.

COHIM, E.; GARCIA, A.; KIPERSTOK, A. Captação e utilização de água pluvial em residências para população de baixa renda em áreas urbanas: estudo de caso. In: SIMPÓSIO DE RECURSO HÍDRICOS DO NORDESTE, 9., 2008. Anais...Bahia, Brasil. 2008.

FONSECA, D. R. Um novo mecanismo para a transformação de resultados provenientes de testes de vida acelerado para resultados estimados em uma condição normal de uso através da utilização da lei de distribuição Maxwell. 2012.146 f. Tese (Doutorado em Engenharia Civil), Universidade Federal Fluminense, Niterói, 2012.

FONTANELA, L. Avaliação de metodologias para dimensionamento de reservatórios para aproveitamento de água pluvial. 2010.68f. Trabalho de Conclusão de Curso (Graduação em Engenharia Civil) - Universidade do Extremo Sul Catarinense, UNESC, Criciúma, 2010.

FRIZZONE, J. A.; ANDRADE, J. A. S.; SOUZA, J. L. M.; ZOCOLER, J. L. Planejamento de irrigação: análise de decisão de investimento. Brasília: Embrapa Informação Tecnológica. 2005. p. 627.

MANTOVANI, E. C.; BERNARDO, S.; PALARETTI, L. F. Irrigação: princípios e métodos. 3.ed. Viçosa: Editora da UFV, 2009. 355 p.

MORUZZI, R. B.; OLIVEIRA, S. C.; CARVALHO, G. Volume do Reservatório de Aproveitamento de Água Pluvial Baseado no Conceito do Balanço de vazões para uma residência unifamiliar. PUBLICATIO UEPG Ciências Exatas e da Terra, Ciências Agrárias e Engenharias, v.14, n.3, p.217-227, 2008.

OLIVEIRA, F. M. B. Aproveitamento de águas de chuva para fins não potáveis no campus da Universidade Federal de Ouro Preto, Minas Gerais. 2008.114 f. Dissertação (Mestrado em Engenharia Ambiental) - Universidade Federal de Ouro Preto, Ouro Preto, 2008.

OLIVEIRA, L. F. C.; CARVALHO, D. F. Regionalização da lâmina suplementar de irrigação e época de plantio da cultura de feijão no estado de Goiás. Revista Brasileira de Engenharia Agrícola e Ambiental, v.7, n.1, p.106-110, 2003.

SAMPAIO, S. C.; LONGO, A. J.; QUEIROZ, M. M. F.; GOMES, B. M.; VILLAS BOAS, M. A.; SUSZEK, M. Estimativa e distribuição da precipitação mensal provável no Estado do Paraná. Acta Scientiarum. Human and Social Sciences, v.28, n.2, p.267 - 272, 2006. 
SOCCOL, O. J.; CARDOSO, C. O.; MIQUELLUTI, D. J. Análise da precipitação mensal provável para o município de Lages, SC. Revista Brasileira de Engenharia Agrícola e Ambiental, v.14, n.6, p.569-574, 2010

SOUZA, W. M. Impactos socioeconômicos e ambientais dos desastres associados às chuvas na cidade do Recife-PE. 2011.140 f. Tese (Doutorado em Recursos Naturais) - Universidade Federal de Campina Grande, Centro de Tecnologia e Recursos Naturais - Campina Grande,2011.

SPERANCETTA, D.; ALVES, J. V.; KRÜGER, C. M. Captação de águas pluviais para abastecimento residencial Da Vinci, v.1, n.1, p. 29-42, 2004.

TOMAZ, P. Aproveitamento de água de chuva: para áreas urbanas e fins não potáveis. 2.ed. São Paulo: Navegar Editora, 2003.

TUCCI, C. E. M. Água no meio urbano. In: BRAGA, B. et al. Águas doces no Brasil: capital ecológico, uso e conservação. 4.ed. São Paulo: Escrituras, 2015. p. 391 - 424.

TUCCI, C. E. M. Gestão de águas pluviais urbanas. In: TUCCI, C. E. M. Ministério das cidades. Unesco, 2005. 